\title{
Health Inequalities During COVID-19 and Their Effects on Morbidity and Mortality
}

This article was published in the following Dove Press journal:

Journal of Healthcare Leadership

\author{
Vaibhav Mishra $\mathbb{D}^{\prime}$ \\ Golnoush Seyedzenouzi' \\ Ahmad Almohtadi (D) \\ Tasnim Chowdhury (iD) \\ Arwa Khashkhusha ${ }^{2}$ \\ Ariana Axiaq ${ }^{3}$ \\ Wing Yan Elizabeth Wong ${ }^{4}$ \\ Amer Harky ${ }^{5-8}$ \\ 'School of Medicine, Faculty of Life \\ Sciences, St. George's, University of \\ London, Cranmer Terrace, London, \\ SWI7 ORE, UK; ${ }^{2}$ School of Medicine, \\ Faculty of Life Sciences, University of \\ Liverpool, Foundation Building, \\ Brownlow Hill, Liverpool, L69 7ZX, UK; \\ ${ }^{3}$ School of Medicine, Faculty of Life \\ Sciences, Queen's University Belfast, \\ Belfast, UK; ${ }^{4}$ Brighton and Sussex Medical \\ School, Faculty of Life Sciences, \\ University of Sussex, Falmer, BNI 9PX, \\ UK; ${ }^{5}$ Department of Cardiac Surgery, \\ Alder Hey Children Hospital, Liverpool, \\ UK; ' ${ }^{6}$ Department of Cardiothoracic \\ Surgery, Liverpool Heart and Chest \\ Hospital, Liverpool, UK; ${ }^{7}$ Liverpool \\ Centre for Cardiovascular Science, \\ University of Liverpool and Liverpool \\ Heart and Chest Hospital, Liverpool, UK; \\ ${ }^{8}$ Department of Integrative Biology, \\ Faculty of Health Sciences, University of \\ Liverpool, Liverpool, UK
}

Correspondence: Amer Harky Department of Cardiothoracic Surgery, Liverpool Heart and Chest Hospital, Liverpool, UK

Email aaharky@gmail.com

\begin{abstract}
Inequalities in health have existed for many decades and have led to unjust consequences in morbidity and mortality. These have become even more apparent during the COVID-19 pandemic with individuals from black and minority ethnic groups, poorer socioeconomic backgrounds, urban and rurally deprived locations, and vulnerable groups of society suffering the full force of its effects. This review is highlighting the current disparities that exist within different societies, that subsequently demonstrate COVID-19, does in fact, discriminate against disadvantaged individuals. Also explored in detail are the measures that can and should be taken to improve equality and provide equitable distribution of healthcare resources amongst underprivileged communities.
\end{abstract}

Keywords: health inequalities, socioeconomic status, geographical location, vulnerable populations, coronavirus

\section{Introduction}

The World Health Organization (WHO) defines health inequities as "avoidable inequalities in health between groups of people within countries and between

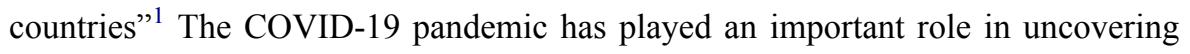
and amplifying numerous health inequalities that already existed within societies and between different population groups. This has led to disastrous and unjust consequences in mortality rates amongst black and minority ethnic groups, vulnerable groups of society such as refugees, asylum seekers and individuals from socioeconomically deprived backgrounds. ${ }^{2,3}$ Inequalities in health during COVID-19 are exacerbated by interweaving risk factors and comorbidities which unfavorably magnify the disease burden and therefore this has been described as a co-occurring, synergistic pandemic for the more underprivileged communities. ${ }^{3}$ Existing governmental priorities and decisions embedded in macro-socio-political infrastructures and global economic forces, across history and cultures, have permitted COVID-19 to discriminate against disadvantaged populations. This review intends to explore this in detail as well as identify strategies which can improve equality and access to healthcare in these challenging times.

\section{Inequalities in Health Amidst the COVID-I 9 Pandemic Health Inequalities}

Much legislation exists to address health inequalities in the UK including the Health and Social Care Act 2012 which addresses inequalities in access to health services and outcomes of different patient groups. Despite this, COVID-19 has 
undoubtedly impacted certain population groups more than others. Mortality rates have been particularly high in the elderly with those aged 90 years and above making up the largest proportion of COVID-19 deaths. ${ }^{4}$ Men have higher mortality rates than women in all age groups; the agestandardized mortality rate (ASMR) for males was 65.1 deaths per 100,000 males compared to 43.3 deaths per 100,000 in females. ${ }^{4}$

People from black and ethnic minority groups have been disproportionately affected by COVID-19. People of all ethnic groups, except those of Chinese background, have a significantly higher risk of being diagnosed with COVID-19 than the white ethnic population. ${ }^{5}$ The risk of serious complications and death as a result of COVID-19 are also increased in these groups. Mortality amongst black people is 2.7 times higher than that those of a white ethnic background. ${ }^{5}$ Considering all COVID-19 related deaths up to the $28^{\text {th }}$ July 2020 , mortality was highest amongst Black African males. ${ }^{5}$ Several reasons for this have been alluded to in recent literature including the presence of comorbidities which are disproportionately greater in minority ethnic groups compared to white ethnic groups. Despite this, adjusting for comorbidities has shown that other factors play a contributory role including geographical location, occupational exposure, socioeconomic status and barriers in accessing healthcare. ${ }^{6,7}$

\section{Geography}

Geography is an established determinant of health with overwhelming evidence linking it to differences in health outcomes as demonstrated by variations in life expectancy, ${ }^{8}$ making it an imperative risk factor to consider in relation to COVID-19. At first glance, geography can be thought of as the physical description of an area created to serve a public purpose, but importantly it creates gradients that separate people by different environments, social capital, local price variations, distribution of healthcare facilities and nature of healthcare delivered. ${ }^{9}$ One of the major geographical distinctions causing health disparities is the distribution of the population between cities and rural areas. ${ }^{10}$

Evidence from the United Kingdom Office for National Statistics (ONS) demonstrates that urban communities have a statistically significant higher COVID-19 related ASMR than rural areas, with 132.8 deaths per 100,000 population for urban major contributions. ${ }^{11}$ This was followed by urban minor conurbations and urban cities and towns. ${ }^{11}$ Rural hamlets and isolated dwellings in a sparse setting had the lowest ASMR of 24.4 deaths per 100,000 population. ${ }^{11}$ A principal reason for the difference in mortality rate is the difference in deprivation between urban and rural communities. ${ }^{12}$ The Index of Multiple Deprivation by the Ministry of Housing, Communities and Local Government established that overall, rural areas tend to be less deprived than urban areas in the United Kingdom. ${ }^{13}$ This index takes into account seven domains including: income deprivation, employment deprivation, education, skills and training deprivation, health deprivation and disability, crime, barriers to housing and services, and living environment deprivation; ${ }^{14}$ all contributors to poorer health outcomes as described by the WHO. ${ }^{15}$ Expectedly, the ONS report, using the same index, provides evidence that the highest ASMR due to COVID-19 in the least deprived areas was less than half of the mortality rate in the most deprived areas. ${ }^{11}$

Nonetheless, rural populations face a unique set of challenges when dealing with COVID-19. These populations are known to have an aging population, ${ }^{16}$ higher burden of preventable diseases such as hypertension and diabetes, and poorer access to healthcare. ${ }^{17}$ There is extensive evidence suggesting that the risk of mortality from COVID-19 is higher in the ageing population, ${ }^{16,18}$ potentially causing the non-ASMR to be higher in rural populations than urban ones. ${ }^{19}$ Moreover, studies suggest that rural communities tend to have a higher burden of preexisting conditions than urban communities. ${ }^{17}$ A population study in the United Kingdom demonstrates that people with type 1 and type 2 diabetes have a significantly higher mortality rate from COVID-19 than those without diabetes, demonstrating how even one preexisting condition can severely impact one's health during the pandemic. ${ }^{20}$ Access to healthcare is also limited in rural areas, often due to limited providers and lack of resources, ${ }^{21}$ making it more difficult for COVID-19 patients to obtain the appropriate care they need. ${ }^{22}$ This is particularly important when the need for COVID-19 testing grows beyond what is reimbursable, forcing some rural providers in private healthcare systems like that of the USA to stop providing care to those who are uninsured. Taking all of this into account, it is crucial that measures are set in place to try and limit the effect of the aforementioned factors on COVID-19 outcomes, albeit some are difficult to control.

It is also important to also consider the effect of the environment on COVID-19 outcomes. A study by CocaciaM $^{23}$ conducted in Italy demonstrates that there is 
a probable link between higher air pollution and cities furthest away from the sea and faster accelerated diffusion of the COVID-19 virus. This suggests that these areas may attract a higher number of cases ultimately increasing the incidence of poor outcomes in the community. However, more studies will be needed to establish a concrete link between these areas and COVID-19.

\section{Socioeconomic Status and Deprivation}

In 1980, Sir Douglas Black devised The Black Report which influenced research around social inequalities in health. The report argued that it was primarily material circumstances such as income, housing, education, diet, employment, and conditions of work that were the chief causes of social inequalities in health. ${ }^{24}$ These views are still generally accepted today; however, it is important to be aware that social inequalities are not the only factors which may contribute to poorer outcomes in individuals. The link between socioeconomic status and development of non-communicable diseases is well documented and more recently supported in a systematic review by Lago et al who concluded that income inequality was associated with worse average health. ${ }^{25}$ There has been limited literature analyzing similar links between socioeconomic status and infectious diseases. However, a 2018 study found higher occurrence rates of infectious diseases as well as poorer outcomes amongst individuals from lower socioeconomic backgrounds. ${ }^{26}$ Some of the mechanisms speculated included poor housing, overcrowding, nutritional deficiencies, poor hygiene, poor working conditions and lack of health education. ${ }^{26}$

Increasing evidence has emerged highlighting that COVID-19 mortality is higher within those who are socioeconomically deprived, on top of having protected characteristics such as disability and pregnancy. A cross-sectional study by Rose et al assessed the association between ethnicity, income deprivation and COVID-19 mortality rates in England and found statistically significantly higher mortality rates in communities experiencing financial hardship. ${ }^{27}$ As well as living in overcrowded housing and continuing active employment in essential occupations during the peaks of the pandemic, those from lower socioeconomic backgrounds also tend to have higher rates of comorbidities such as diabetes, COPD and chronic kidney disease; all of which put further strain on the burden of disease. It is important to consider, however, that the above study was published in the form of a preprint and still to be evaluated by a wider medical community and therefore the conclusions derived must be taken with caution. ${ }^{27}$ Another cross-sectional study of 2595 adults tested for COVID-19 found that both race and poverty were associated with higher risks of hospitalization; however, only poverty and financial hardship was associated with higher risks of escalation to intensive care units. ${ }^{28}$ This suggests that environmental factors such as those associated with poorer socioeconomic backgrounds tend to have more adverse outcomes with COVID-19 when compared to biological factors. The reason for this trend may once again be due to these individuals having to continue active employment where working from home is not feasible and use public transportation, despite national and local lockdowns; in combination both of which may increase an individual's exposure to the viral load and worsen overall prognosis.

Schools worldwide have had to close to limit the gathering of large crowds. This has further contributed to the overcrowding of smaller households. Evidence shows that children from lower socioeconomic backgrounds have had higher rates of positive testing of COVID-19. A crosssectional study by Goyal et al explored these socioeconomic disparities through comparison of positivity rates between separate median family income quartiles. ${ }^{29}$ Children living in households with lower median family income quartiles had the highest rates of positivity compared to those living in households with higher median family income quartiles. The study also highlighted that even after adjustment of socioeconomic variables, significant ethnic and racial disparities remained within the data, with children from black and minority ethnic groups having higher rates of infection when compared to nonHispanic white children. ${ }^{29}$

\section{Inclusion Health Groups of the Society}

The COVID-19 crisis has caused many implications on the population health outcome worldwide and has drastically affected vulnerable groups of the society. This has created a diverse health inequality among different sociodemographic backgrounds and public health policies need to be implemented to deliver health services among vulnerable groups to prevent the dismal outcome. ${ }^{30}$ Homeless people are among individuals which experience health consequences in the current COVID-19 pandemic. Their living arrangements whether formal (shelters or halfway houses) or informal (encampments or abandoned buildings) make them susceptible to worse health outcomes. Congregate living settings are known to be conducive to a disease epidemic and lack of access to healthcare supplies and hygiene setting expedite the 
outbreak of COVID-19. Studies have reported that individuals under the age of 65 facing homelessness are 5-10 times more likely to suffer from chronic physical and mental health illness. ${ }^{30}$ This creates a bigger disease burden in the subgroup and higher rates of mortality. Additionally, drug-seeking behaviors are mostly seen in this vulnerable group which induces multiple comorbidities and more severe illness in case of acquiring the virus.

Furthermore, the Gypsy, Roma and Traveler (GRT) population are among the groups which are currently facing disparity in health outcomes in the current COVID-19 pandemic. Given that they are highly mobile groups of society, they may be socially marginalized, and experience reduced access to healthcare centers. Studies have elicited that throughout the years, GRT population are amongst the most disadvantaged minorities. ${ }^{31}$ Moreover, due to the higher rate of illiteracy and cultural barrier, preventative public health measures can be challenging to implement. Living conditions are also among the determinants of health inequality and due to nomadic nature of their living, individuals in such groups find it challenging to engage with their healthcare services and adhere to measures such as social distancing and hand hygiene. This widens the health disparity which already exists within the population. ${ }^{32}$ Additionally, travelling is one of the main pillars of GRT groups, which may accelerate transmission between communities. Hence, it is vital to generate an accessible healthcare system for this subgroup and to deliver health information in a nondiscriminatory manner.

Refugees and asylum seekers are also among the atrisk population which are currently facing devastating health outcomes in the current climate and pandemic. They are currently experiencing violence, family separation, culture loss and exile from their homeland, and the current pandemic is an ongoing health crisis for this vulnerable group of society. ${ }^{33}$ Due to their poor living circumstances and overcrowded refugee camps, public health measures are deemed challenging to enforce by the current humanitarian establishment to deliver aid. This disproportionally exposes them to the risk of COVID-19 infection and leads to higher morbidity and mortality rate among the community. Due to the lack of available basic sanitation and health resources, COVID-19 has a higher rate of contingency in overpopulated refugee camps. ${ }^{33,34}$ There have been ongoing worries within the health community in Cox's Bazar, Bangladesh which currently host more than 600000 Rohingya refugees. It has been estimated that in case of an outbreak of COVID-19, local hospital capacity will be reached within 58 days and results in exhaustion of medical facilities. ${ }^{35}$ This creates a dilemma where other opportunistic infections such as communicable diseases will result in higher death tolls. There has been limited research done whether coexisting infection results in poorer health outcome in COVID-19 infection; however, WHO has warned the implications which warrants addressing by medical authorities. ${ }^{36}$ Moreover, fear of being deported has resulted in individuals not seeking medical treatment and testing, which is further accentuated by the language barrier. Although healthcare resources are strained in such difficult times, it is vital to priorities the at-risk groups and to encourage a more comprehensive health delivery by NGO's and humanitarian agencies.

Poverty and low socioeconomic status are other welldocumented factors in poor health outcomes, evidence of which can be seen in South Africa; a region with large economic disparity which is extrinsically linked to the severe health disparity. Lockdown measures enacted by the government have put a strain on the most economically challenged groups in society. This, in turn, may create a vicious cycle which would exacerbate the poor health outcomes for the underprivileged members of the society. ${ }^{37}$

\section{Strategies for Improving Equality and Access to Healthcare}

It is fundamental to understand what causes disparities in health if we are to take measures to abolish them. A review article by McCartney et al explored a number of theories that give rise to health inequalities. ${ }^{38}$ The basic principles were derived from the Black Report and the main causes explored included artefact theory, selection theory, behavioral and cultural theories, and structural theory. Of these, the structural theory has proved to be the most pivotal cause of health inequalities and argues that socioeconomic status throughout life causes the differences seen in health outcomes. ${ }^{24,38}$ Equitable distribution of income, wealth, power, safe working environments and access to healthcare within and between different communities is the idealistic approach to improving equality but may be difficult to conceptualize and finetune. Thus, this paper will explore potential strategies from three perspectives: from a governmental and legislative level; local and community angle; and at an individual stance, with a large focus on measures that can improve the socioeconomic status of those from underprivileged backgrounds. 


\section{Legislative and Regulatory Controls}

Evidence shows that poor living conditions make individuals susceptible to numerous health problems ranging from infections, respiratory conditions, injuries, and depression. ${ }^{39}$ Damp, cold, and moldy housing can worsen respiratory conditions such as asthma and those with chronic respiratory conditions tend to have poorer outcomes associated with concurrent COVID-19 infection. Krieger et al discussed substandard housing usually suffered from a lack of safe drinking water, hot water for washing, ineffective waste disposal, inadequate food storage and infestations; all of which can increase transmission of infectious diseases. ${ }^{39}$ Whilst governments can introduce guidelines such as improved standardization of housing, the crux lies in enforcing the minimum requirements set out by governmental housing guidelines in poorer areas with continued close monitoring to ensure the level of quality is maintained. Further interventions to improve internal housing conditions include regular review of warmth and energy efficiency, housing refurbishment and rehousing. ${ }^{40}$ These strategies can ultimately lead to better living conditions and reduced health-related disparities.

\section{Income Support from the government - Tax and Benefit Systems, Professional Welfare Rights Advice in Healthcare Settings}

As previously discussed, deprivation, unemployment and poverty have significant impacts on health outcomes. Various support schemes have been implemented worldwide aiming to impact the disparities in health outcomes between populations. In the UK, one of these measures was the Coronavirus Job Retention Scheme (CJRS), where $80 \%$ of salary costs will be paid by the government. Other support included mortgage holidays, updated rules on evictions, an increase of $£ 20$ per week to Universal Credit and Working Tax Credit claimants and an increase in housing benefit for all. ${ }^{41}$ Furthermore, studies suggest that COVID-19 has major impacts on mental health and thus, reducing financial burdens may lessen the mental health impact of this virus. ${ }^{42}$ By providing this support, governments ensure low-income families are less impacted by stressors that can harm mental and physical health and allow for better opportunities for good health. ${ }^{43}$ These schemes are also particularly important in preventing long-term deprivation, ${ }^{44}$ and in order to promote the uptake of available support schemes during COVID-19, a fundamental step would be to provide adequate funding towards professional welfare rights advice in healthcare settings. There is evidence that welfare rights advice delivered through healthcare settings results in financial benefit, ${ }^{45}$ which in the long-run can prove beneficial in reducing monetary-related health inequalities associated with COVID-19.

\section{Reducing Price Barriers}

Another step government can take is by reducing price barriers to accessing preventative health services, which may potentially lessen the burden of COVID- $19 .^{46}$ Smoking is known to increase mortality in patients with COVID-19. ${ }^{22}$ Public healthcare systems such as the NHS benefit from free smoking cessation services, ${ }^{47}$ but the majority of private systems do not. Thus, governments can step in by subsidizing or waiving the fee for smoking cessation services, in aims of lowering the risks of smoking-related diseases. ${ }^{48}$ With the general population becoming more conscious of their health, many healthcare systems are now using COVID-19 as a motivator for smoking cessation to both improve health outcomes and reduce long-term costs associated with smoking. ${ }^{49}$

Another measure government can uptake is by providing free school meals to children to ensure healthy growth. Countries like the UK are now providing free school meals to all infants and pupils who meet the benefits-related free school meals eligibility criteria. ${ }^{50}$ This measure proves important as it avoids children from lower-income families missing meals which can adversely affect their immediate and long-term health ${ }^{51}$ and reduces the financial burden on families who are unemployed due to COVID-19. To take support one step further, the implementation of reduced or free prescriptions can be considered. In countries with private healthcare systems, access to medications can be expensive which ultimately disadvantage lower income individuals. ${ }^{52}$ Surveys suggest that low-income households take less medications than prescribed to avoid the out-of-pocket cost. ${ }^{53-55}$ Coupled with the financial burden, the population faces amidst the pandemic, funding can be introduced to further support those requiring prescriptions during the pandemic.

\section{Local Community Support for Vulnerable Groups}

From a community level, there are several measures that can be implemented to help reduce disparities. Pregnant and postnatal women were among the at-risk groups of 
population who faced challenges with regards to their continuity of care. ${ }^{56}$ On March 16th, 2020, the UK government declared that pregnant women were categorized as the vulnerable subset of society. Due to the changes in the immune system response during pregnancy, this predisposes individuals at a higher risk of illness severity which has been an ongoing concern in the current pandemic. As such, local NHS trusts have collectively made efforts to ensure all antenatal appointments are provided in full accordance with NICE guidelines, through virtual and in-person consultations. ${ }^{57}$ Practical measures such as scheduling appointments such that a woman can come into hospital once to complete all checks - from bloods to scans, reduces the risk of exposure. ${ }^{58}$

In addition, childcare is another aspect that can be addressed by local communities. ${ }^{59}$ Prior to COVID-19 pandemic, childcare and education accessibility has been deemed challenging for vulnerable groups due to expenses and limited supplies. This has been exacerbated by the current climate and social distancing measures. Furthermore, gender inequality has been highlighted through the crisis, with a larger burden of housework and childcare falling on a mother's shoulders compared to their male partner. ${ }^{60}$ One such method of providing support is the rapid establishment of local charities such as National Health Supporter, Bubble and Heroes to support childcare for front-line workers. There has also been an emergence of online communities to support parents working from home with childcare advice and neighborhood aids.

\section{Improving Accessibility of Services}

Delivery of healthcare needs to accommodate for health disparities seen in the society to address sociodemographic differences which affect population health outcome. Through the course of the pandemic, healthcare delivery has been modified to various clinical templates and moved away from the traditional face-to-face consultation. Clinicians are now employing a more radical approach which has been mostly in forms of remote telephone or video clinics. Hence, this can ensure that there is a more accessible mode of healthcare delivery and a better opportunity for vulnerable groups to access health departments as a majority of the population will have access to a mobile phone. ${ }^{61}$

\section{Individual Efforts}

The efforts of an individual can play a role in reducing healthcare inequalities. A method includes actively changing one's diet. Diet is a modifiable risk factor for chronic diseases including cardiovascular and metabolic disease, and thus contributes to health inequality. Individuals can be motivated to follow the suggested recommendations of five minimum servings of fruit and vegetables a day, reduced consumption of red and processed meat and minimum 140 grams per week intake of oily fish, ${ }^{62}$ in order to lead a healthier lifestyle and ultimately reduce health disparities. However, it is recognized that families or individuals on low income may find it difficult to balance living expenses and meet the nutritional recommendations. Hence, income support such as the furlough schemes in the UK or the stimulus checks in the USA remains vital in supporting such individuals during the pandemic. Ultimately, it is the combination of government legislation, local support and an individual's effort that can push for a reduction in health inequalities.

\section{Conclusion}

COVID-19 has demonstrated the seriousness of the consequences faced by those from underprivileged backgrounds and highlighted the predicament they face between poverty and the pandemic. Action must be taken swiftly to ensure the needs of these individuals are met sufficiently for them to be able to survive this pandemic and be well enough equipped to endure any further strains on global health in the future.

\section{Funding}

No funding obtained.

\section{Disclosure}

The authors report no conflicts of interest related to this work.

\section{References}

1. Who.int. WHO, Key Concepts. [online]; 2020. Available from: https:// www.who.int/social_determinants/thecommission/finalreport/key_con cepts/en/. Accessed 22 October 2020.

2. Dorn AV, Cooney RE, Sabin ML. COVID-19 exacerbating inequalities in the US. Lancet. 2020;395(10232):1243-1244. doi:10.1016/S01406736(20)30893-X

3. Bambra C, Riordan R, Ford J, Matthews F. The COVID-19 pandemic and health inequalities. J Epidemiol Community Health. 2020;74 (11):964-968. doi:10.1136/jech-2020-214401

4. Ons.gov.uk. Deaths involving COVID-19, England and Wales - Office for National Statistics. Available From: https://www.ons.gov.uk/people populationandcommunity/birthsdeathsandmarriages/deaths/bulletins/ deathsinvolvingcovid19englandandwales/deathsoccurringinjune2020\# characteristics-of-those-dying-from-covid-19. Accessed November 9, 2020. 
5. Ons.gov.uk. Updating ethnic contrasts in deaths involving the coronavirus (COVID-19), England and Wales - Office for National Statistics. Available at: https://www.ons.gov.uk/peoplepopulationand community/birthsdeathsandmarriages/deaths/articles/updatingethnic contrastsindeathsinvolvingthecoronaviruscovid19englandandwales/ deathsoccurring2marchto28july2020. Accessed January 11, 2020.

6. Kirby T. Evidence mounts on the disproportionate effect of COVID-19 on ethnic minorities. Lancet Respir Med. 2020;8 (6):547-548. doi:10.1016/s2213-2600(20)30228-9

7. Aldridge R, Lewer D, Katikireddi S, et al. Black, Asian and Minority Ethnic groups in England are at increased risk of death from COVID-19: indirect standardisation of NHS mortality data. Wellcome Open Res. 2020;5:88.

8. Dummer TJ. Health geography: supporting public health policy and planning. CMAJ. 2008;178(9):1177-1180. doi:10.1503/cmaj.071783

9. Rice N, Smith PC. Ethics and geographical equity in health care. $J$ Med Ethics. 2001;27(4):256-261. doi:10.1136/jme.27.4.256

10. Anderson TJ, Saman DM, Lipsky MS, Lutfiyya MN. A cross-sectional study on health differences between rural and non-rural U.S. counties using the County Health Rankings. BMC Health Serv Res. 2015;15:441.

11. Ons.gov.uk. Deaths involving COVID-19 by local area and socioeconomic deprivation - Office for National Statistics [Internet]. 2020. Available from: https://www.ons.gov.uk/peoplepopulationandcommunity/birthsdeathsand marriages/deaths/bulletins/deathsinvolvingcovid19bylocalareasanddepriva tion/deathsoccurringbetween1marchand31july2020\#english-index-ofmultiple-deprivation. Accessed January 11, 2020.

12. The Area Based Analysis Unit, Office for National Statistics 1. Understanding patterns of deprivation. Reg Trends. 2009;41:93-114. doi: $10.1057 /$ rt.2009.7

13. GOV.UK. Rural deprivation statistics [Online]; 2020. Available from: https://www.gov.uk/government/statistics/rural-deprivation-statistics. Accessed January 11, 2020.

14. World Health Organisation. Poverty and health [Internet]. 1st ed Paris: OECD Publications Service; 2020. Available from: https:// www.who.int/tobacco/research/economics/publications/oecd_dac_ pov_health.pdf. Accessed 6 December 2020.

15. Fougère B, Aubertin-Leheudre $M$, Vellas B, et al. Clinical research for older adults in rural areas: the MINDED study experience. Age. 2016;38(2):30. doi:10.1007/s11357-016-9892-3

16. Richman L, Pearson J, Beasley C, Stanifer J. Addressing health inequalities in diverse, rural communities: an unmet need. SSM Popul Health. 2019; 7:100398.

17. Mueller AL, McNamara MS, Sinclair DA. Why does COVID-19 disproportionately affect older people? Aging. 2020;12 (10):9959-9981. doi:10.18632/aging.103344

18. Romero Starke K, Petereit-Haack G, Schubert M, et al. The Age-Related Risk of Severe Outcomes Due to COVID-19 Infection: A Rapid Review, Meta-Analysis, and Meta-Regression. Int J Environ Res Public Health. 2020;17(16):5974.

19. Holman N, Knighton P, Kar P, et al. Risk factors for COVID-19-related mortality in people with type 1 and type 2 diabetes in England: a population-based cohort study. Lancet Diabetes Endocrinol. 2020;8 (10):823-833. doi:10.1016/s2213-8587(20)30271-0

20. Weisgrau S. Issues in rural health: access, hospitals, and reform. Health Care Financ Rev. 1995;17(1):1-14.

21. Ranscombe P. Rural areas at risk during COVID-19 pandemic. Lancet Infect Dis. 2020;20(5):545. doi:10.1016/S1473-3099(20) 30301-7

22. Lang AE, Yakhkind A. Coronavirus Disease 2019 and Smoking: how and Why We Implemented a Tobacco Treatment Campaign. Chest. 2020;158(4):1770-1776. doi:10.1016/j.chest.2020.06.013

23. Coccia M. Factors determining the diffusion of COVID-19 and suggested strategy to prevent future accelerated viral infectivity similar to COVID. Sci Total Environ. 2020;729:138474. doi:10.1016/j. scitotenv.2020.138474
24. Gray AM. Inequalities in health. The Black Report: a summary and comment. Int J Health Serv. 1982;12(3):349-380. doi:10.2190/ XXMM-JMQU-2A7Y-HX1E

25. Lago S, Cantarero D, Rivera B, et al. Socioeconomic status, health inequalities and non-communicable diseases: a systematic review. Z Gesundh Wiss. 2018;26(1):1-14. doi:10.1007/s10389-017-0850-Z

26. Pini A, Stenbeck M, Galanis I, et al. Socioeconomic disparities associated with 29 common infectious diseases in Sweden, 2005-14: an individually matched case-control study. Lancet Infect Dis. 2019;19(2):165-176.

27. Rose TC, Mason K, Pennington A, et al. Inequalities in COVID19 mortality related to ethnicity and socioeconomic deprivation. medRxiv. 2020.

28. Muñoz-Price LS, Nattinger AB, Rivera F, et al. Racial Disparities in Incidence and Outcomes Among Patients With COVID-19. JAMA Netw Open. 2020;3(9):e2021892. doi:10.1001/jamanetworkopen.2020.21892

29. Goyal MK, Simpson JN, Boyle MD, Badolato GM, Delaney M, McCarter R. Cora-Bramble D. Racial and/or Ethnic and Socioeconomic Disparities of SARS-CoV-2 Infection Among Children. Pediatrics. 2020;146(4):e2020009951. doi:10.1542/peds.2020-009951

30. Tsai J, Wilson M. COVID-19: a potential public health problem for homeless populations. Lancet Public Health. 2020;5(4):e186-e187. doi:10.1016/S2468-2667(20)30053-0

31. Armitage R, Nellums LB. COVID-19 and the Gypsy, Roma and Traveller population. Public Health. 2020;185:48. doi:10.1016/j. puhe.2020.06.003

32. McFadden A, Siebelt L, Gavine A, Atkin K, Bell K. Gypsy, Roma and Traveller access to and engagement with health services: a systematic review. Eur J Publ Health. 2018;28:74-81. doi:10.1093/eurpub/ckx226

33. Alemi Q, Stempel C, Siddiq H, Kim E. Refugees and COVID-19: achieving a comprehensive public health response. Bull World Health Organ. 2020;98(8):510-510A. doi:10.2471/BLT.20.271080

34. Eiset AH, Wejse C. Review of infectious diseases in refugees and asylum seekers-current status and going forward. Public Health Rev. 2017;38:22. doi:10.1186/s40985-017-0065-4

35. Subbaraman N. 'Distancing is impossible': refugee camps race to avert coronavirus catastrophe. Nature. 2020;581(7806):18. doi:10.1038/d41586-020-01219-6

36. Who.int. Coronavirus disease (COVID-19): tuberculosis. Available from: https://www.who.int/news-room/q-a-detail/tuberculosis-and-the -covid-19-pandemic. Accessed January 11, 2020.

37. Mbunge E. Effects of COVID-19 in South African health system and society: an explanatory study [published online ahead of print, 2020 Sep 11]. Diabetes Metab Syndr. 2020;14(6):1809-1814. doi:10.1016/ j.dsx.2020.09.016

38. McCartney G, Collins C, Mackenzie M. What (or who) causes health inequalities: theories, evidence and implications? Health Policy (New York). 2013;113(3):221-227. doi:10.1016/j.healthpol.2013.05.021

39. Krieger J, Higgins DL. Housing and health: time again for public health action. Am J Public Health. 2002;92(5):758-768. doi:10.2105/ ajph.92.5.758

40. Thomson H, Thomas S, Sellstrom E, Petticrew M. The health impacts of housing improvement: a systematic review of intervention studies from 1887 to 2007. Am J Public Health. 2009;99(Suppl 3):S681S692. doi:10.2105/AJPH.2008.143909

41. Power M, Doherty B, Pybus K, Pickett K. How COVID-19 has exposed inequalities in the UK food system: the case of UK food and poverty. Emerald Open Res. 2020;2:11.

42. Dubey S, Biswas P, Ghosh R, et al. Psychosocial impact of COVID-19. Diabetes Metab Syndr. 2020;14(5):779-788. doi:10.1016/j.dsx.2020.05.035

43. Tinson A Living in poverty was bad for your health long before COVID-19 | the Health Foundation. The Health Foundation. Available from: https://www.health.org.uk/publications/long-reads/liv ing-in-poverty-was-bad-for-your-health-long-before-COVID-19. Accessed January 11, 2020. 
44. Reijneveld SA, Verheij RA, de Bakker DH. The impact of area deprivation on differences in health: does the choice of the geographical classification matter? J Epidemiol Community Health. 2000;54 (4):306-313. doi:10.1136/jech.54.4.306

45. Adams J, White M, Moffatt S, Howel D, Mackintosh J. A systematic review of the health, social and financial impacts of welfare rights advice delivered in healthcare settings. BMC Public Health. 2006;6:1. doi:10.1186/1471-2458-6-81

46. Soskolne V. Preventive health behaviors and physician visits: relevance to health inequality. Isr J Health Policy Res. 2015;4:9.

47. Gibson JE, Murray RL, Borland R, et al. The impact of the United Kingdom's national smoking cessation strategy on quit attempts and use of cessation services: findings from the International Tobacco Control Four Country Survey. Nicotine Tob Res. 2010;12(Suppl 1): S64-S71. doi:10.1093/ntr/ntq119

48. Berlin I, Thomas D, Le Faou AL, Cornuz J. COVID-19 and Smoking. Nicotine Tob Res. 2020;22(9):1650-1652. doi:10.1093/ ntr/ntaa059

49. Elling JM, Crutzen R, Talhout R, de Vries H. Tobacco smoking and smoking cessation in times of COVID-19. Tob Prev Cessat. 2020;6:39.

50. outbreak. GOV.UK. Providing school meals during the coronavirus (COVID-19) Available from: https://www.gov.uk/government/publi cations/covid-19-free-school-meals-guidance/covid-19-free-schoolmeals-guidance-for-schools. Accessed January 11, 2020.

51. Zeballos E, Todd JE. The effects of skipping a meal on daily energy intake and diet quality [published online ahead of print, 2020 May 13]. Public Health Nutr. 2020;1-10. doi:10.1017/ S1368980020000683

52. Kesselheim AS, Avorn J, Sarpatwari A. The High Cost of Prescription Drugs in the United States: origins and Prospects for Reform. JAMA. 2016;316(8):858-871. doi:10.1001/jama.2016.11237

53. Mojtabai R, Olfson M. Medication costs, adherence, and health outcomes among Medicare beneficiaries. Health Aff. 2003;22 (4):220-229. doi:10.1377/hlthaff.22.4.220
54. Piette JD, Heisler M, Wagner TH. Cost-related medication underuse among chronically ill adults: the treatments people forgo, how often, and who is at risk. Am J Public Health. 2004;94(10):1782-1787. doi:10.2105/ajph.94.10.1782

55. Safran DG, Neuman P, Schoen C, et al. Prescription drug coverage and seniors: how well are states closing the gap? Health Aff. 2002: W253-W268. doi:10.1377/hlthaff.w2.253

56. Wong SF, Chow KM, Leung TN, et al. Pregnancy and perinatal outcomes of women with severe acute respiratory syndrome. Am J Obstet Gynecol. 2004;191:292-297.

57. NICE. Antenatal care for uncomplicated pregnancies. UK: national Institute for health and care excellence; 2008. Available from: https:// www.nice.org.uk/guidance/cg62. Accessed January 11, 2020.

58. RCOG, Royal College of Midwives, Royal College of Paediatrics and Child Health, Public Health England and Public Health Scotland. Coronavirus (COVID-19) infection and pregnancy; 2020. Available from: https://www.rcog.org.uk/en/guidelines-research-services/guide lines/coronavirus-pregnancy/. Accessed January 11, 2020.

59. Hashikawa AN, Brousseau DC, Singer DC, Gebremariam A, Davis MM. Emergency department and urgent care for children excluded from child care. Pediatrics. 2014;134:e120-e127.

60. Del Boca D, Oggero N, Profeta P. Women's and men's work, housework and childcare, before and during COVID-19. Rev Econ Househ. 2020;18(4):1001-1017.

61. Iyengar K, Mabrouk A, Jain VK, Venkatesan A, Vaishya R. Learning opportunities from COVID-19 and future effects on health care system. Diabetes Metab Syndr. 2020;14(5):943-946. doi:10.1016/j. dsx.2020.06.036

62. Scientific Advisory Committee on Nutrition [Internet]. Webarchive. nationalarchives.gov.uk; 2020. Available from: https://webarchive. nationalarchives.gov.uk/20090108192101/http://www.sacn.gov.uk/ pdfs/nutritional_health_of_the_population_final_oct_08.pdf. Accessed January 11, 2020.
Journal of Healthcare Leadership

\section{Publish your work in this journal}

The Journal of Healthcare Leadership is an international, peer-reviewed, open access journal focusing on leadership for the health profession. The journal is committed to the rapid publication of research focusing on but not limited to: Healthcare policy and law; Theoretical and practical aspects healthcare delivery; Interactions between healthcare and society and evidence-based practices; Interdisciplinary decision-making;

\section{Dovepress}

Philosophical and ethical issues; Hazard management; Research and opinion for health leadership; Leadership assessment. The manuscript management system is completely online and includes a very quick and fair peer-review system. Visit http://www.dovepress.com testimonials.php to read real quotes from published authors. 